\title{
COVID-19 Symptoms Can Prolong Seasonal Flu Infection Symptoms and Recovery Times Among Obese African American Female Population
}

\author{
Smart Asare ${ }^{1}$ (D) $\cdot$ Aubin Sandio $^{1} \cdot$ Mohan Palla $^{2} \cdot$ Eric Ayers $^{3} \cdot$ Abraham Arhin $^{1} \cdot$ Paul Elangwe $^{4} \cdot$ Nkechi Ihezie $^{5}$
}

Accepted: 14 February 2021 / Published online: 25 February 2021

(C) This is a U.S. government work and not under copyright protection in the U.S.; foreign copyright protection may apply 2021

\begin{abstract}
According to several studies, obesity increases rates of metabolic syndrome plus other comorbidities like diabetes and cardiovascular diseases. However, little evidence exists as to whether obesity assists in the prolongation of COVID-19 and seasonal flu-like symptoms especially among African American 55-74-year age groups. The purpose of this study is to show that COVID-19 symptoms can prolong recovery times and symptoms of seasonal flu-infected obese African Americans. The aim of the study is to investigate risk factors which include modifiable (i.e., obesity) and non-modifiable (i.e., age, race) effect on prolongation and recovery times for some inpatient COVID-19 and seasonal flu-infected African American from a single hospital in Detroit, MI.
\end{abstract}

Keywords LL-37 levels $\cdot$ Viral shedding $\cdot$ Seasonal flu $\cdot$ Obesity $\cdot$ COVID-19

\section{Introduction and Background}

COVID-19 is an acute infectious respiratory disease caused by infection with coronavirus subtype SARS-CoV-2. Transmission happens through respiratory droplets via coughing sneezing, avoiding hand washing after long periods,

This article is part of the Topical Collection on Covid-19

Smart Asare

sasare@email.davenport.edu

Aubin Sandio

asandio@med.wayne.edu

Mohan Palla

mpalla@med.Wayne.edu

Eric Ayers

eayers@med.wayne.edu

Abraham Arhin

Abrahamarhin@gmail.com

1 Wayne State University, 4201 St Antoine, Detroit, MI 48201, USA

2 Kingman Cardiovascular Institute, Kingman, AZ, USA

3 Internal Medicine \& Pediatrics, Wayne State \& DMC hospital, Wayne State University, 4201 St Antoine, Detroit, MI 48201, USA

4 Edinburgh, USA

5 Bronx, USA and rubbing unwashed hands on eyes, plus not wearing facemasks in crowded areas. Many of these modes of transmission are similar to routes of infection by seasonal influenza A flu infections. A wide spectrum of severity starting with dry cough, difficulty breathing or dyspnea, fever, headache, and muscle fatigue is reported by majority of patients with both infections. Obesity promotes chronic inflammation through release of cytokines like tumor necrosis factor (TNF- $\alpha$ ), IL$1 \beta$, and IL-6 [1] and triggers unsustainable immune response to viral infections like COVID-19 and seasonal influenza flu [1]. High cytokines (cytokine storm) promotes lung failure among female obese African Americans [1].

Studies have shown that antimicrobial peptide LL-37, a pertinent factor for the innate immunity, has high antibacterial and antiviral activity $[2,3]$. Reports suggest that the expression level of LL-37 peptide is increased by vitamin $\mathrm{D}$ and that serum LL-37 level tend to be low when the serum vitamin $\mathrm{D}$ level is low [4, 5]. Fat deposition around the neck and face promotes the production of pro-inflammatory cytokines [6], increasing inflammation. Viruses like influenza A which causes seasonal flu infect mucosa and in some patients, lungs, creating free radical formation and causing inflammation.

Low peptide LL-37 in obese patients allows viruses like influenza A and particularly coronavirus subtype SARS-CoV2 to increase severity of shedding and reinfection cycles. Shedding duration is the onset of illness to the time the patient 
experiences recovery. Obese adults shed the seasonal influenza flu virus at a rate of $104 \%$ [7].

\section{Methods}

Obesity trends data with BMI $\geq 30$ from 2013-2016; this was gathered from NHANES Center for Disease Control and prevention (CDC) [8]. About 2000 African American patients were studied from April 20 to November 16, 2020. Out of this, 400 (200 males and 200 females) were studied from September 25 to November 16, 2020. Imaging of lung samples were taken from obese African American patients with COVID-19 and seasonal flu infections. Images were taken on or after day 6 of management of symptoms. Most patients were discharged after second round of imaging. That is by day $13 / 14$.

Inclusion criteria include female and male African Americans with BMI $\geq 30$ and those who were infected with COVID-19 and seasonal flu starting from September 25 to November 16, 2020, within the ages of 55-74, and, finally, those whose lung chest $\mathrm{x}$-ray did not improve on or after 21 days of hospitalization and management. Exclusion criteria include African American patients aged 55-64 years whose symptoms improved or resolved prior to or on day 19 , those who had symptoms prior to or after the research period, Hispanic patients whose symptoms and imaging did not improve after 21 days, and those with BMI $\leq 29$ and below whose symptoms did not improve after 21 days.

\section{Results}

\section{Discussions}

Data collection and calculation of percentage differences among different races from Tables 1 and 2 showed the

Table 1 Obesity percentages by race

\begin{tabular}{lc}
\hline Whites only & \\
\hline White male & $36.9 \%$ \\
\hline White female & $38.8 \%$ \\
Hispanics or Latino only & \\
Male Hispanic & $41.2 \%$ \\
Female Latina & $48.4 \%$ \\
Blacks or African American only & \\
African American male & $37.5 \%$ \\
African American female & $56.1 \%$ \\
\hline
\end{tabular}

Table 2 Obesity (BMI $\geq 30.0)$ percentages for African Americans only Male

\begin{tabular}{ll}
\hline $55-64$ years & $39.3 \%$ \\
\hline $65-74$ years & $40.2 \%$ \\
Female & \\
55-64 years & $48.2 \%$ \\
$65-74$ years & $43.5 \%$ \\
\hline
\end{tabular}

following: Whites only [females $(38.8 \%)$ - males $(36.9 \%)]=1.9 \%$ difference; Hispanics only [Latina $(48.4 \%)$ - Latino $(41.2 \%)]=7.2 \%$ difference; and Blacks only [females $(56.1 \%)$ - males $(37.5 \%)]=18.6 \%$ difference. Female African American obese patients were more affected with obesity and its complications especially starting with $\mathrm{BMI} \geq 30$. This prompted more investigation within this specific group and patients who reported to the hospital with COVID-19 and seasonal flu infections within the city of Detroit, MI and were obese were the focus of the research, particularly from September 25 to November 16, 2020.

We expanded the study period to see how seasonal flu patients who got infected with COVID-19 had any other disease characteristics or risk factors or past history of diabetes or renal diseases etc. The only comorbidity significantly impacting the study was obesity since treatment options had little to no effect on weight reduction on the patients. Out of a total of 2000 obese patients seen (that is, from April 20, 2020, to November 16, 2020) at DMC hospital, 1600 patients had image findings similar to Fig. 1 while the remaining 400 patients to Fig. 2. Out of this number, 200 males and 200 females were followed by scheduling appointments. Seasonal flu symptoms start late September. So, 400 obese African Americans who had Fig. 2 were followed from September 25 to November 16. 2020. These patients have no other disease characteristics except obesity. Obesity has multiple future risk factors which is very highly unlikely to influence image studies within our study period. Patients had no past medical history. African Americans in general due to low arginine levels and high salt diets have a higher risk for hypertension especially after age 50 . We made sure patients in the study were not being treated from high blood pressure or hypertension. Those that showed improvement in their symptoms (200 males and 140 females) were managed with supportive care. Sixty (60) female obese African American patients had Fig. 3 by 20 October 2020 and continued till the end of the study November 16, 2020, where they progressed to Fig. 4. These patients never showed improvement from several symptomatic management options. 


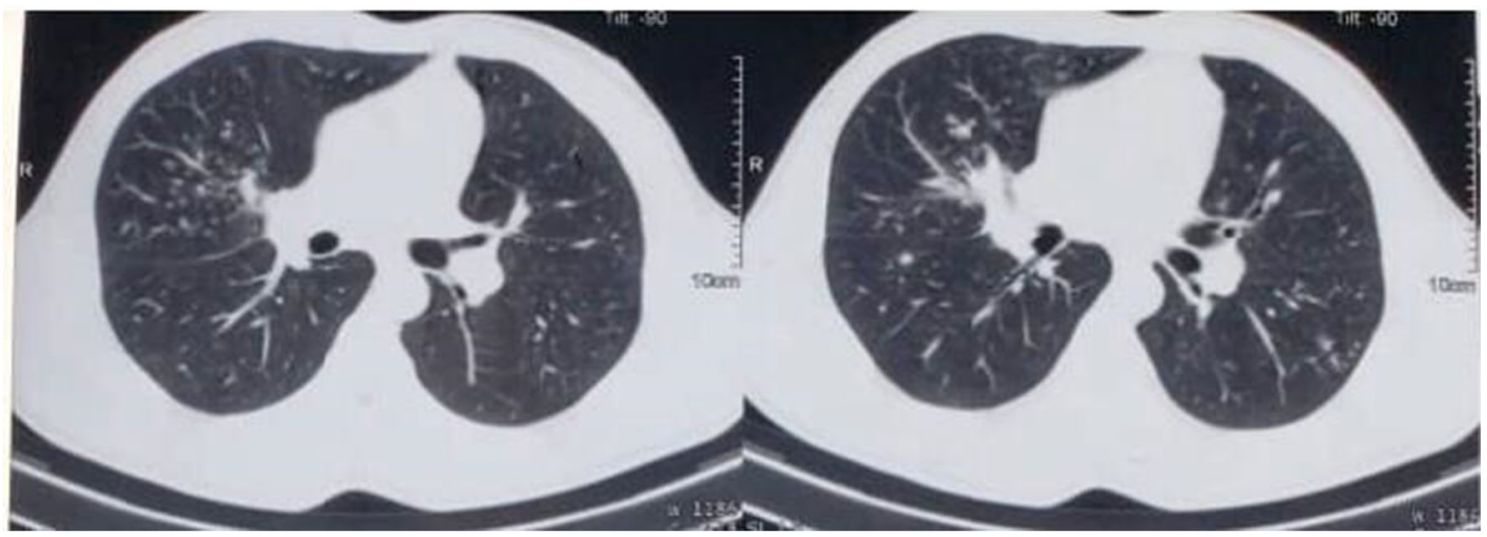

Fig. 1 Female obese African American patients who reported to the hospital on day one/two

Figure 1 shows x-ray for asymptomatic patients infected with COVID-19 and seasonal flu infection in obese female African American while Fig. 2 shows mildly symptomatic patients who were managed with empirically with dexamethasone and remdesivir. Most of them had symptom resolution by day 14 while some patients showed some improvement before being discharged. These patients with Fig. 2 continued to see their primary care physicians as their symptoms continued to improve and resolve. Some patients remained ill and
Fig. 3 shows some nodules of patients who were not improving despite additional management with procalcitonin and supportive care after 14 days of admission. Figure 4 shows mediastinal lymphadenopathies as well as diffuse patchy pulmonary infiltrates. Some of these patients went on to develop chronic conditions like acute respiratory distress syndrome (ARDS) and interstitial pulmonary fibrosis.

The key here is that, despite management and adequate care, lung findings particularly for obese African American

INTAKE CLERK
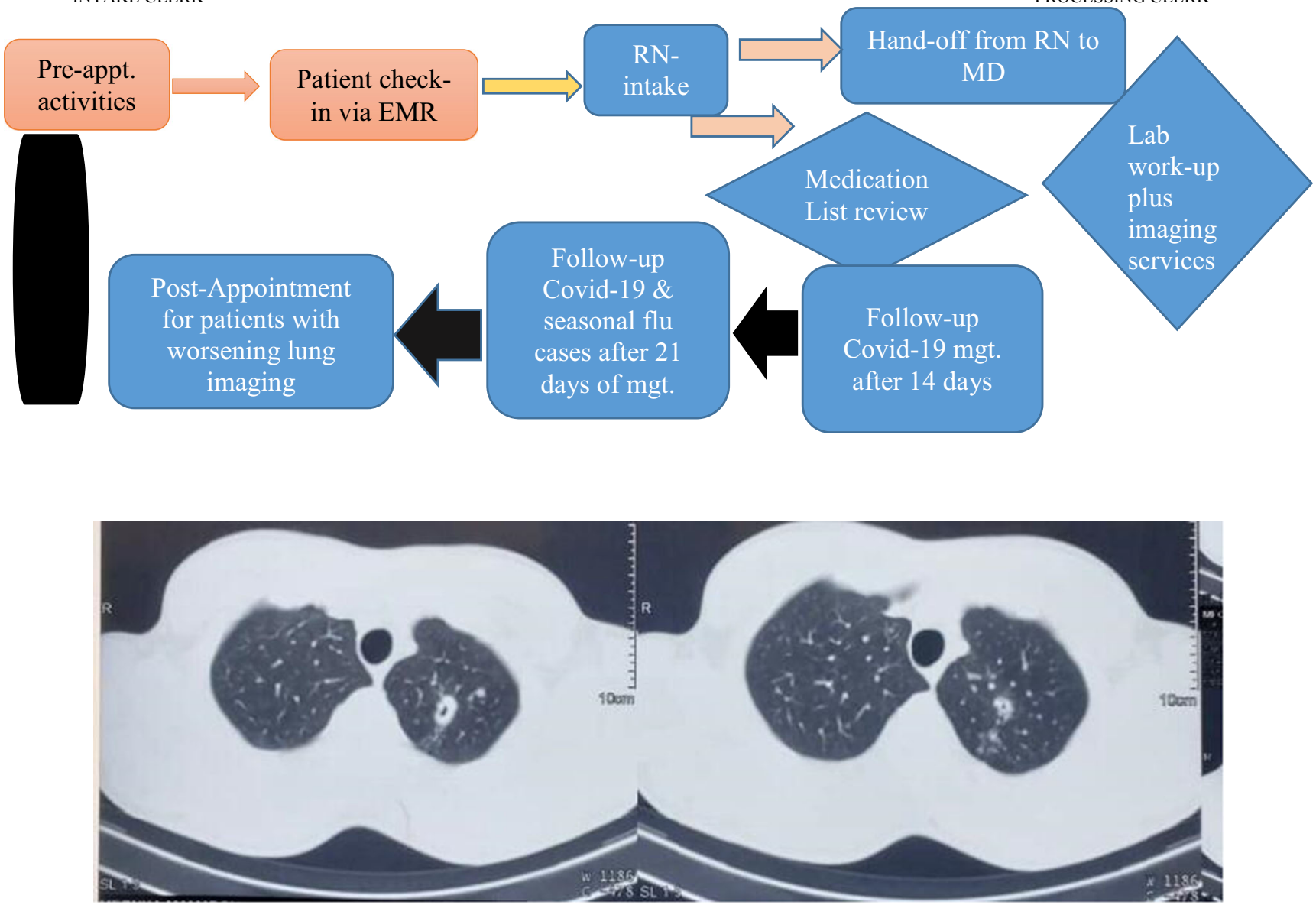

Fig. 2 Day 6/7 imaging studies of obese female African Americans 


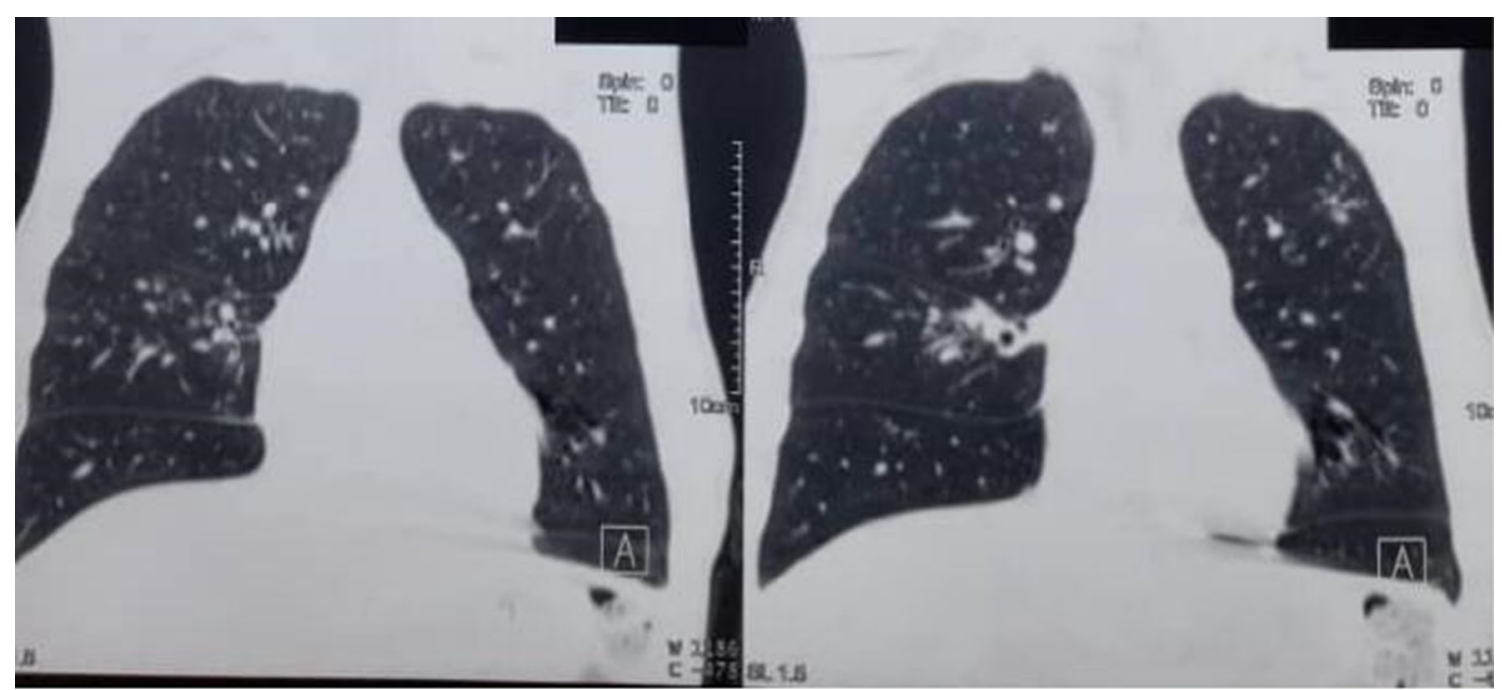

Fig. 3 Day 13/14 of lung x-ray showing disease spreading

females who got infected with COVID-19 and seasonal influenza flu infections within 55-74 age groups within the study period did not improve after 21 days of hospitalization. Reinfection, immune-compromised, lowest peptide LL-37 levels, viral shedding, and chronic inflammation from obesity may be some reasons why African American females who are obese and get infected with COVID-19 and seasonal flu even after management of their symptoms continue to have longer recovery times. Several studies have linked increasing obesity trends to increasing viral shedding. One thing about our human bodies and pathogens is that we do not put our systems at risk for pathogens to have easy access to cause infections because when they do, there is a wide variety of infections they cause potentially making it impossible to manage.

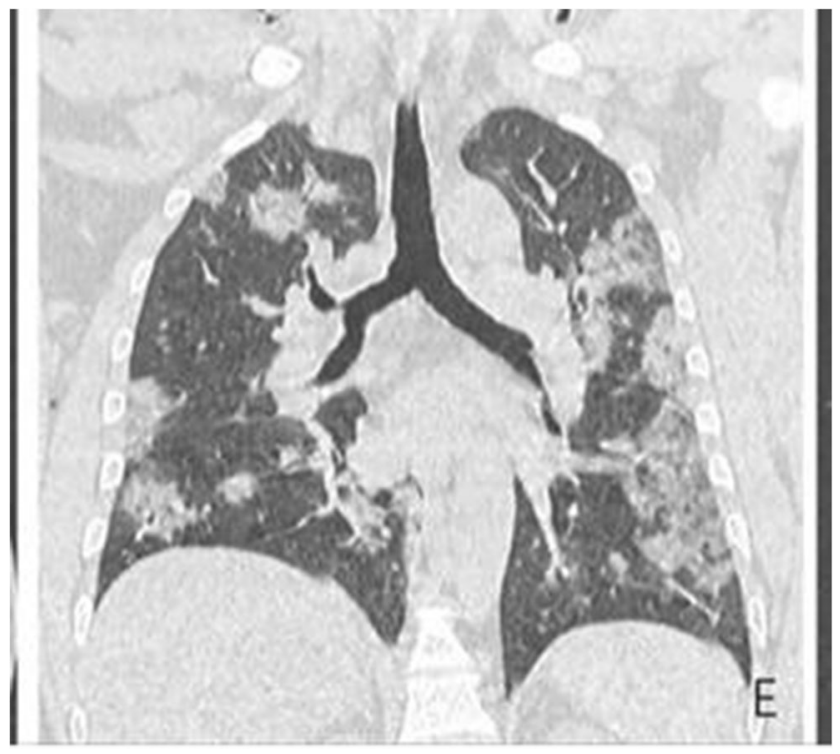

Fig. 4 Female obese patients on or after day 21 of management
Limitations to the study include the following: based on CDC data, we focused solely on the African American obese race. Due to the high amount of deaths in Detroit (Oakland County), we focused our study at one hospital inpatient/outpatient. Detroit, MI has a high population of African Americans especially obese females that report to the hospital for care. Our study focused in this particular region.

\section{Conclusions}

Obesity alters immune function by promoting chronic inflammation which prolongs symptoms and recovery times of African Americans infected with seasonal flu-like and COVID-19. Obese African American females who were infected with COVID-19 and seasonal flu were more likely than males to have prolonged recovery times while disease severity and age was just about equal. The duration of viral shedding had no correlation with COVID-19 and seasonal flu infection severity.

Code Availability Non-applicable

Author Contributions Data collection process:

1. US regional census data was gathered from CDC free of charge. This information can be verified at any time and it is free. (Dr. Nkechie Ihezie)

2. Patients that were seen as inpatients/outpatients in one hospital in the city of Detroit (Dr. Eric Ayers, and Dr. Abraham Arhin)

3. Data collection of outpatient/inpatient, conducting research, collecting lab imaging, writing the manuscript (Dr. Smart Asare, Dr. Aubin Sandio, Dr. Paul Elangwe)

4. Interpreting results of lab imaging, results, discussions, and reviewing (Dr. Mohan Palla, Dr. Smart Asare, Dr. Eric Ayers, \& Dr. Aubin Sandio) 
Data Availability US regional census data was gathered from CDC free of charge; patients visits; inpatient/outpatient; non-applicable.

\section{Declarations}

Consent to Participate Non-applicable

Consent for Publication Non-applicable

Conflict of Interest The authors declare no competing interests.

\section{References}

1. Renu K, Prasanna LP, Gopalakrishnan VA. Coronaviruses pathogenesis, comorbidities and multi-organ damage - a review. Life Sci. 2020;255:117839. https://doi.org/10.1016/j.lfs.2020.117839.

2. Tripathi S, Wang G, White M, Qi L, Taubenberger J, Hartshorn KL. Antiviral activity of the human cathelicidin, LL-37, and derived peptides on seasonal and pandemic influenza A viruses. PLoS One. 2015;10:e0124706. https://doi.org/10.1371/journal.2015.124706.

3. Sørensen OE, Follin P, Johnsen AH, Calafat J, Tjabringa GS, Hiemstra PS, et al. Human cathelicidin, hCAP-18, is processed to the antimicrobial peptide LL-37 by extracellular cleavage with proteinase 3. Blood. 2001;97:3951-9. https://doi.org/10.1182/ blood.V97.12.3951.

4. Hansdottir S, Monick MM, Hinde SL, Lovan N, Look DC, Hunninghake GW. Respiratory epithelial cells convert inactive vitamin D to its active form: potential effects on host defense. J Immunol. 2008;181:7090-9 PubMed, PubMed Central, Google Scholar.

5. Kanda N, Hau CS, Tada Y, Sato S, Watanabe S. Decreased serum LL-37 and vitamin D3 levels in atopic dermatitis: relationship between IL-31 and oncostatin M. Allergy. 2012;67:804-12. https://doi. org/10.1111/j.1398-9995.2012.02824.x CrossRef, PubMed, Google Scholar.

6. He CS, Fraser WD, Tang J, et al. The effect of 14 weeks of vitamin D3 supplementation on antimicrobial peptides and proteins in athletes. J Sports Sci. 2016;34:67-74. https://doi.org/10.1080/ 02640414.2015.1033642 CrossRef PubMed Google Scholar.

7. Hannah EM, Roger L, Nery S, et al. Obesity increases the duration of influenza A virus shedding in adults. J Infect Dis. 2018;218:1378-82.

8. CDC. (2017). Obesity trends among African American population by gender. Retrieved from: https://www.cdc.gov/nchs/hus/ contents2017.htm\#058.

Publisher's Note Springer Nature remains neutral with regard to jurisdictional claims in published maps and institutional affiliations. 